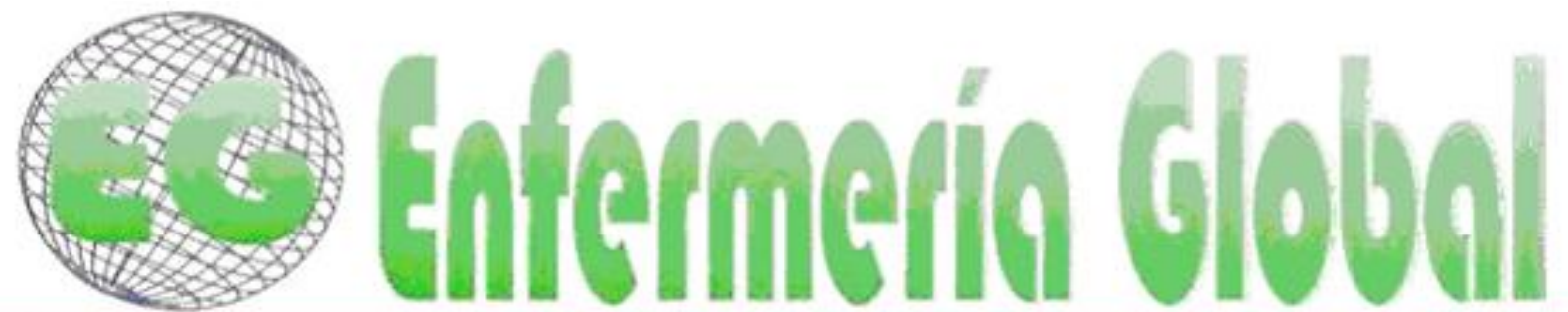

$N^{\circ} 33$

www.um.es/egloball

\title{
ENSAYOS
}

\section{El cuidado de enfermería: una visión integradora en tiempos de crisis}

Nursing care: an integrating vision in times of crisis

\author{
"Guevara, B **Evies, A *Rengifo, J **Salas, B ${ }^{* * *}$ Manrique, D ***Palacio, C. \\ *Doctora en Enfermeria. Profesora Titular. E-mail: bguevara5918@hotmail.com **Doctoranda en \\ Educacion. Profesora Asociada ***Doctoranda en Enfermeria. Profesora Agregada. Escuela de \\ Enfermeria. Facultad de Ciencias de la Salud. Universidad de Carabobo. Venezuela.
}

Palabras clave: Cuidado de Enfermeria; Visión Integradora; Cuidado Humano..

Keywords: Nursing Care; Integrating Vision; Human Care.

\section{RESUMEN}

Existen diversas organizaciones y movimientos humanitarios a nivel mundial que tratan de luchar contra las expresiones de deshumanización, sin embargo, continúa la presencia de situaciones que son causas de dolor en el mundo, por lo que debemos constituir una sociedad para que el mundo sea civilizado, vivir por la calidad de vida y no por acumular cifras estadísticas. El cuidado es una característica común de todos los seres vivos. Por consiguiente, el cuidado humano se reconoce como un concepto universal, inherente a la humanidad. Heidegger, el filósofo por excelencia del cuidado, reconoce que éste es "una constitución ontológica, siempre subyacente a todo lo que el ser humano emprende, proyecta y hace". Enfermería como profesión de naturaleza social intenta que su personal, bajo una óptica humanista, ayude a la persona solicitante del cuidado a reforzar potencialidades y/o minimizar desequilibrios en su estado de salud, por ello reconoce al ser humano como un ser complejo, misterioso, estructurado por diversas dimensiones que van de lo orgánico a lo espiritual, de lo tangible a lo intangible; con inclusión del aspecto social e histórico, que lo define como un ser de interrelaciones permanentes consigo mismo y el mundo. Bajo esta perspectiva, en enfermería, se procura reconocer que la persona cuidada es una entidad única, poseedora de atributos: conciencia, intelecto, dignidad, emociones, sentimientos y saberes, por lo tanto, el cuidado en enfermería asume una dimensión humanista y comprensiva del ser, cuya subjetividad está estructurada por sus vivencias y significados, sentimientos, emociones, intuiciones, razonamientos

\section{ABSTRACT}

Nowadays, there exist several organizations of humanitarian movements all over the world which try to fight against the dehumanization expressions; however there still exists the presence of situations which are the reasons of pain in the world. That is why we must construct a better and civilized world in which people worries about the quality of life instead of accumulating statistical numbers .Care is a common feature of all human beings. Therefore, human care is recognized as a universal concept, inherent in 
humanity. Heidegger, the philosopher for excellence of care, recognizes that this is "an ontological constitution that is always underlying to all what the human beings begin, project and make." Nursing as a profession of social nature tries that its staff, under an humanistic perspective, helps the person interested in care to reinforce his /her abilities and /or to minimize imbalances in her /his state of health .That is why it recognizes the human beings as a complex, mysterious and structured in several dimensions being that range from the organic to the spiritual, from the tangible to the intangible , including the social and historical aspect, which defines it as a being of permanent relationships with himself and the world. Under this point of view, nursing tries to recognize that the cared person is a unique entity which has attributes such as: awareness, intellect, dignity, emotions, feelings and knowledge. Therefore, the nursing care assumes a comprehensive and humanistic dimension of the human being whose subjectivity is structured by his experiences ,meanings, feelings, emotions , intuitions , and reasoning .

\section{INTRODUCCIÓN}

Actualmente enfrentamos una crisis civilizacional generalizada, evidenciada a través de una serie de conducta en el hombre que se resumen en una falta de cuidado tanto para el mismo como para los demás, como son: La explotación y tráfico infantil, las guerras, la desnutrición espiritual, la intolerancia, el daño ecológico, la pobreza extrema, la desvalorización de los valores personales, cristianos e institucionales, la codicia donde lo material supera a lo espiritual entre otros aspectos que identifican este siglo XXI a pesar de los avances científicos y tecnológicos.

Existen diversas organizaciones y movimientos humanitarios a nivel mundial que tratan de luchar contra las expresiones de deshumanización, sin embargo, continúa la presencia de situaciones que son causas de dolor en el mundo, por lo que debemos constituir una sociedad más humana y vivir por la calidad de vida. Se necesitan personas conscientes y comprometidas en la construcción de una civilización planetaria más humana, más sensible al dolor ajeno y a la necesidad del prójimo.

Se requiere de una nueva filosofía que sea holística, ecológica y espiritual que nos identifique como ciudadanos del mundo con nuestras obras. Una de las profesiones humanistas de naturaleza social es Enfermeria; cuya práctica profesional debe estar fundamentada en ofrecer un cuidado humanizado, donde no solo se trate el órgano o sistema que está enfermo, sino que también se aborden las diferentes dimensiones del receptor del cuidado. Es fundamental, reflexionar sobre la visión holística de la persona, visualizándolo permanentemente como una unidad, cuya concepción es imperativa moralmente en las ciencias humanistas, en un intento por minimizar la fragmentación y/o cosificación de la persona y considerarlo como sujeto, en esta sociedad del conocimiento, de grandes avances científicos y tecnológicos. Algunos autores como Martha Rogers, definen al humano como "Un ser unitario, irreductible, que posee su propia integridad y un conjunto de características que son más y diferentes de la suma de sus partes. Además, el ser humano es un sistema abierto, en un proceso continuo de interacciones con un entorno eternamente cambiante" (1). Morín, reconoce que el ser humano es: "Físico, biológico, síquico, cultural, social e histórico. Es una unidad compleja que hay que restaurarla, de tal manera que cada uno desde donde esté tenga conocimiento y conciencia al mismo tiempo de su identidad compleja y de su identidad que es común a todos los demás humanos" (2)

Enfermería como profesión de naturaleza social intenta que su personal, bajo una óptica humanista, ayude a la persona solicitante del cuidado a reforzar potencialidades $\mathrm{y} / \mathrm{o}$ minimizar desequilibrios en su estado de salud, por ello reconoce al ser humano como un ser complejo, misterioso, estructurado por diversas dimensiones que van de lo orgánico a lo espiritual, de lo tangible a lo intangible; con 
inclusión del aspecto social e histórico, que lo define como un ser de interrelaciones permanentes consigo mismo y el mundo. Bajo esta perspectiva, en enfermería, se procura reconocer que la persona cuidada es una entidad única, poseedora de atributos: conciencia, intelecto, dignidad, emociones, sentimientos y saberes, por lo tanto, el cuidado en enfermería asume una dimensión humanista y comprensiva del ser, cuya subjetividad está estructurada por sus vivencias y significados, sentimientos, emociones, intuiciones, razonamientos. La dimensión humanista del ente humano, en enfermería, nos ubica en armonía con pensadores existencialistas, quienes cuestionan la tendencia positivista, reduccionista propia de la filosofía occidental. El enfoque existencialista reconoce que la verdad está presente en la interioridad de todo ser humano único manantial de la verdad viva, por tanto allí encontramos la verdadera esencia que favorece el cuidado significativo en enfermería.

Esta práctica de Enfermeria humanizada implica la trascendencia más allá de la simple relación entre humanos. Exige la presencia significativa de la persona que cuida y de la persona receptora del mismo. Esta presencia significativa implica ver, escuchar, tocar y sentir a través de un proceso de empatía que debe estar presente en la relación interpersonal. La enfermera cuidadora debe acercarse al mundo del otro para comprenderlo y fortalecerlo en su propia capacidad de cuidado; para esto, dicho profesional ha de reconocer su propia existencia ${ }^{(3)}$.

Las ideas precedentes permiten concretar que la persona es un ser único, con características propias, poseedor de una individualidad irrepetible, con un espíritu gregario desde que inicia su desarrollo en el útero materno, por lo que obligatoriamente establece una relación constante con su medio externo e interno, lo que implica un proceso de adaptación a los diversos cambios que confronta permanentemente.

Es en este contacto permanente con el mundo, cuando la persona tiene la oportunidad de someterse a las exigencias del medio ambiente y de responder como un ser integral a los estímulos del mismo, en que experimenta y vive sus propias experiencias, las que se traducen en comportamientos para expresarse, lo que favorece su proceso de adaptación. Tales ideas se apoyan en el enfoque de Calixta Roy, quien en su modelo de adaptación, reconoce que "el individuo es un ente biopsicosocial en interacción constante con su ambiente. Interacción que lo obliga a adaptaciones continuas" (4). Vivir es responder, responder es comportarse, comportarse es adaptarse para seguir transformando el mundo. Es identificar el entorno, conocer el mundo, es crucial para el hombre, para su permanencia, su sobrevivencia y, con los otros hombres, explorarlos, darse y dar cuenta de lo conocido, enseñar y aprender para poder vivir, para poder convivir, para poder transformar ${ }^{(5)}$

Dentro de este orden de ideas, se considera que la persona es un ser complejo, poseedor de una mente con capacidad para pensar, y discernir sobre las diversas situaciones que experimenta en su cotidianidad. Tal discernimiento o reflexión es una fuente de conocimiento, le permite tomar decisiones guiadas por su sistema de valores, los cuales son aprendidos y reforzados en la familia, la escuela, los medios de comunicación y la sociedad. Entre dichos valores están el respeto, la solidaridad, la autoestima, la justicia, la autonomía entre otros.

Heidegger, resalta que todo conocimiento del ser humano exige la interrogante ¿Qué es el ser? Por lo tanto, la fenomenología como método "abre la posibilidad de 
responder de manera concreta a la pregunta por el sentido del ser". El autor reconoce que "responder dicha interrogante implica dirigir la vista, comprender, tener acceso como formas constitutivas del preguntar" (6). Desarrollar la interrogante por el ser es ver a través de un ente, comprender mediante una interpretación profunda, es adentrarse en aquella parte intangible de la persona, su realidad émica, en la concepción del ser ahí (Dasein) o modo particular de ser, que es el humano.

El Dasein, es la manera de ser, característicamente humano o Ser- en- el- mundo. Según Heidegger, M. lo resaltante del ser humano "es que no existe un ser, sin un mundo y no hay un mundo que no se defina en relación de un ser para el cual dicho mundo, es su mundo" (6). El Dasein responde y reacciona de acuerdo con la percepción de sí mismo y de su mundo circundante. En consecuencia, el enfoque heideggeriano, fundamentado en la fenomenología como método, favorece la posibilidad de acceder a la persona y desarrollar la interrogante que pregunta por el ser. Esto es importante para determinar los elementos ontológicos de la naturaleza del ser, que orientan y ayudan al personal de enfermería para cuidar de sí y de otros.

Esto implica que el ser humano jamás ha de ser tratado como un medio, u objeto, pues es un ser pensante, libre y autónomo, por consiguiente es una persona cuya dignidad hay que respetar. La dignidad de la persona hay que reconocerla siempre, independientemente de sus rasgos físicos, psíquicos o sociales y del grupo cultural al que pertenezca.

Al hacer la referencia a la dignidad humana, es necesario traer a colación el concepto de condición humana expresado por Sartre, "es el marco general en el que invariablemente se desenvuelve la vida humana; donde este marco básico de la vida humana queda resumido en cuatro actividades que son: a) Estar arrojado en el mundo; b) Tener que trabajar; c) Vivir en medio de los demás; d) Ser mortal" (7).

Jaspers reconoce que la condición humana es la propia existencia del ser, en la que centró su interés al expresar que "el ser no es sino lo que puede y debe ser. Este ser soy yo mismo como existencia". Por lo tanto, "la existencia es lo que se relaciona consigo mismo y por consiguiente con la trascendencia" (8) La existencia humana va más allá de la subjetividad, por cuanto uno mismo sólo se realiza en su comunicación con otro, lo que hace posible la realización del ser ${ }^{(8)}$. Por su parte, Buber, estima que "el individuo es un hecho de la existencia en la medida en que entra en relaciones vivas con otros individuos" (9). Por lo tanto, "el hecho fundamental de la existencia humana es el hombre con el hombre".

Al reflexionar sobre la condición humana o existencia, se infiere que la vida de una persona transcurre desde el momento mismo de la concepción hasta su muerte. En este periodo, su devenir histórico como ser humano atesora un conjunto de experiencias vitales, las cuales le sirven para desarrollar su propia condición humana. Esto determina que dicha condición es inherente a la persona misma, concebida como un ser multidimensional, donde predomina la pluralidad de pensamiento, como característica singular y fundamental. La condición humana es una constante universal y cada persona la adquiere a través de su relación con otros. 
En este sentido, se puede conceptuar la condición humana como una construcción, mediante un proceso de aprendizaje, de naturaleza interactiva, en el que se obtienen normas, valores, creencias, conocimientos, actitudes, comportamientos. La misma está sujeta a la síntesis espacio-tiempo; es decir, se adquiere en un contexto sociocultural específico y en un tiempo determinado. Por consiguiente, dicha condición es digna de ser respetada.

Al reconocer el valor de la dignidad, la vida de la persona toma un rango cualitativo similar al de otro congénero, es por esto, que una amplia corriente filosófica defienda que la ética es la fundamentación racional posible para los derechos humanos pues ésta es la que reconoce la dignidad de los vivientes con rostro humano y a partir de este reconocimiento trata de discernir de qué son dignos esos seres y qué obligaciones debemos cumplir con ellos. "La vida es algo sagrada por lo tanto todas las decisiones éticas deben basarse en la reverencia hacia la misma" (10). Desde el punto de vista religioso para algunas personas, la vida es un don de Dios y por ello sólo a Dios corresponde quitarla. Para otros, la vida es una facultad irrenunciable; como premisa necesaria que hace posible todos los demás derechos ${ }^{(10)}$. Es verdad, que la vida no nos pertenece al no depender su origen de nosotros mismos; pero, es un don del que se provee al ser vivo, por lo tanto, es un bien absoluto que hay que cuidar y proteger. El derecho a la vida es una exigencia para la persona pues a nadie le es permitido disponer de algo que no es suyo, en este caso, su propia vida. Todos tenemos el deber de proteger y conservar nuestra vida, debido al compromiso de autorrespeto, derivado de que la persona ni se ha hecho a sí misma, ni ella se ha dado el valor y la dignidad que posee ${ }^{(11) .}$

La vida, "no posee el mismo valor para quien la concibe como un don de Dios, indisponible para el hombre, que para quien la considera una mera propiedad inmanente a ciertos seres" (12).

Lo mencionado anteriormente sobre algunos conceptos de la vida nos hace reflexionar necesariamente sobre el cuidar de sí mismo y el cuidar de otros, como fenómeno existencial de la persona, al considerar que es inmanente a la vida misma, de ahí la razón por la que todo ser vivo con rostro humano a través de su evolución, ha tenido la necesidad de realizar acciones protectoras para cuidar de sí y cuidar a los demás. Es la base en la que se sustenta la continuidad, la multiplicación y la protección de la existencia humana, por lo tanto, toda acción humana ha de ser cuidadora para sí y para otros, extensible hasta la naturaleza y el cosmos.

Según el Diccionario Enciclopédico Océano el cuidado significa "asistir, guardar, conservar, mirar uno por su salud, preocuparse de algo o prevenirse contra algo" (13). En este sentido, Colliere, especifica que "es asegurar la continuidad de la vida del grupo, de la especie.... Es mantener la vida asegurando la satisfacción de un conjunto de necesidades indispensables para la vida, pero que son diversas en su manifestación"(14).

Watson, J. reconoce al cuidado en conjunto con el amor, en que ambos estructuran la energía psíquica primordial y universal. Constituyen la piedra angular de nuestra 
humanidad; asimismo, el nutrimento de estas necesidades (cuidado y amor) da sentido a la condición de ser humano ${ }^{(1)}$

La autora valora que las personas poseen tres esferas del ser: "mente, cuerpo y alma y permitir la expresión de estas fuerzas conduce a un mejor entendimiento de uno mismo y de los demás" (15). Por ello, Watson, J. prioriza que:

\begin{abstract}
El humano necesita cuidado y amor, y éstos a menudo han de ser vistos como lo máximo, pues la humanidad está para sobrevivir, lo que implica que los seres humanos necesitamos llegar a ser más cuidadosos, más afectivos, más amorosos. El cuidado y el amor son lo más universal, lo más sublime y lo más misterioso de las fuerzas cósmicas. ${ }^{(16)}$
\end{abstract}

El enfoque Watsoniano enfatiza que el ideal, y el valor del cuidado es un punto de partida, una postura, una actitud, que tiene que convertirse en: deseo, una intención, un compromiso, y un juicio consciente que se manifiesta en actos concretos. "El cuidado humano está relacionado con las respuestas humanas intersubjetivas a las condiciones de salud- enfermedad; y las interacciones persona-entorno" (15). El cuidado humano efectivo puede ser demostrado y practicado interpersonalmente; sin embargo, "el proceso de relación interpersonal está definido dentro de un contexto transpersonal; que trasciende a cada ser humano, y se mueve en círculos concéntricos del yo hacia el otro, al medio ambiente, a la naturaleza y al universo" (17)

Los enfoques precedentes, referentes al cuidado humano permiten reflexionar con respecto al mismo. Este junto con el amor estructuran la energía que mueve al universo, y que en su forma excelsa podría ser el espíritu, el cual consideramos es la forma más elevada de la persona, que aunque es intangible, nos reafirma la idea de aceptar que somos mente, cuerpo y espíritu, y como tal respondemos unitariamente. Esto nos hace comprender la necesidad de autodescubrirnos, autoconocernos, querer y apreciar cada parte de nuestro cuerpo, lo que nos exige tratar de vivir en armonía con nosotros mismos, con los demás y con la naturaleza.

El cuidado como valor moral representa el ideal de enfermería por mantener el respeto a la dignidad de la persona solicitante del cuidado. Enfatiza el sentido axiológico en la toma de decisiones éticas para ejecutar acciones cuidadoras. Como relación interpersonal, el cuidado favorece la interacción significativa entre persona cuidada y persona cuidante, en la que se incorporan: conocimientos, sentimientos, responsabilidades, opiniones, actitudes, acciones, con lo que se demuestra preocupación e interés por su alter ego. El cuidado como afecto significa la dedicación afectiva y efectiva del profesional de enfermería para proporcionar la ayuda a la persona que necesita ser cuidado.

En cuanto al cuidado como intervención terapéutica, consideramos importante resaltar esta dimensión por cuanto es una oportunidad de los profesionales de enfermería al estar frente a la persona que por uno u otro motivo requiere acciones cuidadoras. Es la oportunidad para demostrar sus habilidades de presencia 
significativa al acercarse y despertar en aquella, la suficiente confianza y reconocer que la presencia de dicho profesional va más allá de la ejecución de procedimientos necesarios, pues el cuidado significativo debe estar determinado por el saber escuchar atentamente, a su vez involucra un proceso de aprendizaje de saber escucharnos a nosotros mismos para poder escuchar atentamente al otro. Saber cuándo tocar y la manera de cómo hacerlo, el tocar es un acto significativo, dado que a través de él se transmite seguridad, afecto, sinceridad, calor entre muchos otros sentimientos y pienso que el tocar muchas veces dice más que las palabras, y esto es importante para la persona receptora del cuidado.

El ver es otra actitud cuidadora, que determina la presencia significativa del profesional de enfermería, quien debe aprender a interpretar en cada expresión quinestésica lo que el paciente intenta manifestar, lo que siente en el momento del contacto interpersonal. La persona en sus expresiones corporales puede demostrar: soledad, temor, dolor, desesperación, desinformación, dudas, ansiedad entre otros sentimientos; y es aquí donde el profesional tiene la oportunidad de ejercer su rol de cuidadora, mediante la empatía, la comprensión, el respeto, la orientación pertinente, el apoyo emocional y espiritual; todo ello unido a las habilidades, destrezas y la seguridad en la ejecución de los procedimientos técnicos. Por consiguiente, el profesional de enfermería debe apoyar a la persona cuidada por medio de actitudes y acciones que muestren interés por su bienestar y su aceptación como persona que piensa, siente, y padece. Evitar considerarlo como un ser cosificado, que sólo responde a un desequilibrio biológico manifestado por signos y síntomas.

En el contexto del cuidado humano es imprescindible reflexionar sobre el cuidar de sí como imperativo esencial para proteger el sí mismo considerado por Jersild como: Un conjunto de pensamientos y sentimientos que constituyen la conciencia de la existencia individual de la persona, su concepción sobre quién es y lo que es. El sí mismo de una persona es la suma total de todo lo que ella puede llamar suyo e incluye un sistema de ideas, actitudes, valores, compromisos. Es el ambiente subjetivo de la persona ${ }^{(18)}$

Las definiciones coincidentes de las citadas autoras, reflejan lo que es el sí mismo, por consiguiente, se reconoce que éste es lo que somos como personas, es nuestra naturaleza biopsicosociocultural y espiritual, es nuestro propio yo, nuestra singular y única forma de ser humano, sin exceptuar nuestra relación con otros seres humanos. En este sentido, es relevante destacar que el sí mismo exige medidas protectoras e implícitas en el cuidar de sí.

El cuidar de sí es un acto vital, representado en la infinita y compleja variedad de actividades que la persona realiza para resguardar y mantener su existencia. El cuidar de sí como construcción humana es el resultado de un proceso socializador, donde la persona aprende: las costumbres, los hábitos, las actitudes, las creencias, los valores, propios de grupos sociales influyentes; pero también representa la autovaloración, la sensibilidad, el compromiso que se tenga a sí misma.

El cuidar de sí incluye, entre otros aspectos, el cuidado a: la salud, los pensamientos, las actitudes, los comportamientos, las emociones, los valores, las necesidades 
biopsicosociales; incluso los bienes y todo aquello que nos genere bienestar, sin lesionar el bienestar de los demás.

En relación con el cuidar de sí, Colliere, M. lo expresa bajo la denominación de cuidar para referirse a "un acto individual, que uno se da a sí mismo cuando adquiere autonomía" (19). Por su parte, Mayeroff, M. reconoce que el cuidar de sí exige a la persona identificar, comprender y gratificar sus necesidades, convertirse en su protector y asumir la responsabilidad primigenia de cuidar su existencia. Dicha responsabilidad es conceptuada por el citado filósofo, como un acto voluntario, auténtico, consciente, que constituye la autorrespuesta para satisfacer sus propias necesidades, por lo que es válido tener en cuenta los atributos que caracterizan al cuidar de otros: "dedicación, confianza, paciencia, humildad, sinceridad" (20).

En este sentido, Foucault, M. al referirse al cuidar de sí, lo denomina las tecnologías del yo que:

Permiten a los individuos efectuar, por cuenta propia o con la ayuda de otros, cierto número de operaciones sobre su cuerpo y su alma, pensamientos, conducta, o cualquier forma de ser para obtener así, una transformación de sí mismos, con el fin de alcanzar cierto estado de felicidad, pureza, sabiduría o inmortalidad ${ }^{(21)}$

Martínez Ocaña, E. reconoce que el cuidar de sí representa "una sabiduría que vamos aprendiendo a lo largo de nuestros procesos evolutivos, porque cada etapa del camino tiene sus necesidades y cuidados específicos" (22)

Los enfoques sobre el cuidar de sí, presentados por Colliere, Mayeroff, Foucault y Martínez permiten reconocer que dicho concepto exige concienciar su permanente presencia en la persona. Es como se dijo antes, una construcción humana, resultado del aprendizaje de esquemas socioculturales determinantes e influyentes, pues cada cultura tiene sus modelos, juicios de valor e incluso tabúes, con respecto al cuidado humano y al cuidar de sí.

\section{REFLEXIONES FINALES}

El ser humano es un ser integral que se desenvuelve dentro de un ambiente, con una realidad social que lo distingue; en él influyen un sinnúmero de características biológicas, psicológicas, sociales y espirituales que lo hacen poseedor de una individualidad propia al pensar, discernir, sentir, tomar decisiones y actuar. En consecuencia, el profesional de Enfermeria que labora en organizaciones vinculadas con la salud debe tener siempre presente que la persona es un ser integral y el ente principal de la atención en salud; poseedor de valores y creencias derivadas de una cultura que hay que considerar, al momento de proporcionarle el cuidado, esto, sin duda nos conducirá hacia una enfermería basada en una practica de cuidado humanizado. Para lograr comprender a la persona como un todo, se requiere reflexionar sobre los elementos básicos que estructuran la condición humana, entre los cuales figuran los valores, los cuales, son los ejes fundamentales por los que se orienta la vida humana y constituyen a su vez, la clave del comportamiento de las personas.

La persona está en la naturaleza y en el universo para trascender a través de acciones que lo distingan como un ser racional y emotivo lo cual queda expresado, entre otros valores, por el amor, la solidaridad, la responsabilidad en su relación continua y recíproca con las demás personas, animales, plantas, en fin con la 
naturaleza. El Arquitecto Universal (Dios) nos permite estar presentes en esta vida en un momento determinado, lo que implica aprovecharlo para cumplir la misión significativa de cuidar a todos los seres vivos humanos o no. Esto, de una u otra manera, contribuye a nuestro crecimiento holístico como personas y como profesionales de enfermería, pues permite desarrollarnos espiritual, emocional, y mentalmente; esto se traduce a su vez, en sentirnos bien con nosotros mismos y con los demás, lo que sin duda se reflejará en nuestra practica profesional.

\section{REFERENCIAS BIBLIOGRÁFICAS}

1) Marriner Tomey, Ann y Raile, Martha Modelos y Teorías en Enfermería. MadridEspaña. Editorial Harcourt Brace. Cuarta Edición. 1999. p. 147.

2) Morin, Edgar (2001). Los Siete Saberes Necesarios para la Educación del Futuro. Colombia. Editorial Delfín Ltda. 2001. p. 17.

3) Sánchez, Beatriz. 2000. La Fenomenología: Un Método de Indagación para el Cuidado de Enfermería. Bogotá-Colombia. Editorial Unibiblos. 2000.

4) Brunner, Lilian y Suddarth, Doris (1999). Enfermería Médico Quirúrgica. México. Editorial Interamericana McGraw Hill. Volumen I. 1999. p. 5.

5) Urbina, Secundino (2005). Epistemología de la Salud. Venezuela. Editado por el Instituto de Altos Estudios en Salud Pública (IAESP) “Dr. Arnoldo Gabaldón”. 2005. p. 27.

6) Heidegger Martín. El Ser y el Tiempo. México. Fondo de Cultura Económica. Traductor: José Gao. 1991. p. 220.

7) Sartre, Jean Paul . El Existencialismo es un Humanismo. Buenos Aires-Argentina. Ediciones del 80. 1985. p. 51

8) Jaspers, Karl (1974). Filosofía de la Existencia. Argentina. Ediciones Aguilar Argentina, S.A. Traductor: Luís Rodríguez Aranda. 1974. p. 16

9) Buber, Martín. ¿Qué es el Hombre?. Argentina. Editorial Fondo de Cultura Económica. Segunda Reimpresión. Traductor: Eugenio Imaz. 1990.

10) Rumbold, Graham (2000). Ética En Enfermería. México. Editorial McGraw Hill Interamericana. Tercera Edición. 2000. p. 73.

11) Ufema, Joy (2000). Análisis Ético sobre la Eutanasia. Revista Nursing. Vol. 18. № 4. Editorial Lippincott Williams\& Wilkins. Edición Española. España. 2000. pp. 30- 31.

12) Cely, Galindo G. (2004). Ethos Vital y Dignidad Humana. Bogotá-Colombia. Colección Bioética Pontificia Universidad Javeriana. 2004. p. 89

13) Diccionario Enciclopédico Océano Uno. Color. Editorial Océano. BarcelonaEspaña. 2004. p. 466.

14) Collierie, Marie F. (1993). Promover la Vida. España. Editorial McGraw Hill Interamericana de España. Traductor: Loreto Rodríguez Méndez. 1993. pp. 6-7

15) Kozier, Bárbara; ERB, Glenora; BERMAN, Audrey y Otros. Fundamentos de Enfermería. Conceptos, Proceso y Práctica. Madrid-España. Editorial McGraw- Hill Interamericana. Séptima Edición. 2005. p. 78.

16) Walker, J. y Neuman, B. Nursing Models: Education, Research, Practice and Administration. Nueva York. NLN Press. 1996 p. 15

17/) Watson, Jean . Teoría del Cuidado Transpersonal. Nueva York. Traducido por: Jorge Gómez. 1996. p. 17

18) Radünz, Vera. Cuidando e se Cuidando. Brasil. Editora Cultura e Qualidade. 1998.p. 1.

19) Collierie, Marie F. Promover la Vida. España. Editorial McGraw Hill Interamericana de España. Traductor: Loreto Rodríguez Méndez. 1993. p. 234

20) MAyeroff, Milton. A Arte de Servir Ao Próximo Para Servir a si Mesmo. Brasil. Editorial Record. Traductora: Cristina Carvalho Boselli. 1971: p. 62. 
21) Foucault, Michel. Tecnologías del Yo. España. Ediciones Paidos. Segunda Edición. Traductora: Mercedes Allendesalazar. 1991. p. 48.

22) Martínez Ocaña, Emma. Aprender la Sabiduría del Cuidado de Si Mismo. Revista Confer. España. № 179. 2007. pp. 495-526. 